\title{
Covid-19 Therapeutic Prospects: Cardiotoxicity Concerns
}

\section{Olawale Adeyemi, BS, MD*}

Xavier University School of Medicine, Aruba

\section{*Corresponding author: Olawale Adeyemi, BS, MD, Xavier University School of Medicine, 23 Santa} Helenastraat, Oranjestad, Aruba

There has been extensive research on developing a treatment regimen for COVID-19. Coadministering Chloroquine and Azithromycin have shown promising results in infected people. However, these medications have a peculiar side effect; QT prolongation. Physicians should be aware of the populations taking them and routine EKGs are recommended in these candidates.

Since December 2019, there was an outbreak of a novel coronavirus disease (COVID-19), which was first reported in Wuhan, China. However, the spread has taken on pandemic proportions that have affected several countries across the globe in just a matter of weeks with the figures currently rising. Unfortunately, to date there are no vaccines or medicines approved for this novel infection. However, numerous clinical trials are being launched worldwide to test coronavirus treatments that include some drug repositioning and even repurposing for COVID-19. In a recent trial with patients on COVID-19 treatment [1], $100 \%$ of patients treated with hydroxychloroquine in combination with the macrolide antibiotic azithromycin were cured in comparison with $57.1 \%$ in patients treated with hydroxychloroquine alone, and $12.5 \%$ in the control group. In recent years, there has been researching on the antiviral properties of both medications. Chloroquine and Hydroxychloroquine have been used in the treatment of HIV with mixed results [2]. Azithromycin is active in vitro against Zika and Ebola viruses $[3,4]$. The ability of these drugs to inhibit other coronaviruses, such as SARS-CoV-1, has been explored with promising results [5].

Early in the $20^{\text {th }}$ century, intense demands for an effective quinine substitute launched the discovery and evaluation of a series of organic compounds (beginning with methylene blue), which led to pamaquine and quinacrine after World War I and ultimately produced chloroquine (CQ) in 1934 [6]. Recognition of the value of chloroquine was delayed, and it was not brought forward until it was reevaluated in the United States and designated the drug of choice against malaria near the end of World War II [7]. Chinese experts recommend that mild, moderate and severe COVID-19 cases (without contraindications to $C Q$ ) be treated with 500 milligrams of $\mathrm{CQ}$ twice daily for 10 days [8]. Years of safety data show that hydroxychloroquine can cause cardiac ECG QT prolongation and subsequent arrhythmias, including torsades de pointes and can prolong the QT correction (QTc), even when taken as recommended [9].

In a previous study, torsades de pointes was reported in about $1 \%$ of patients with QT prolongation after exposure to azithromycin [10].

The proposed chloroquine and azithromycin combination drug therapy for COVID-19 brings along with it some major cardiotoxic concerns. If chloroquine or hydroxychloroquine coadministered with azithromycin end up being the miracle drugs, considering their risks, caution should be taken administering them in certain populations. Of special interest would be those patients that may be infected with COVID-19 and have a known prior history of underlying conditions such as congenital long QT syndromes or electrolyte imbalances particularly potassium and calcium. Furthermore, patients who are currently on medications that equally prolong the QT interval (tricyclic antidepressants, antipsychotics, and even some anti-emetics) who might be infected with COVID-19 are also a population of special interest. Monitoring routine EKGs in these groups of patients is recommended. 


\section{Ethics Declaration}

\section{Competing interests}

The author declares no competing interest.

\section{References}

1. Gautret $P$, Lagier JC, Parola P, Hoang VT, Meddeb L, et al. (2020) Hydroxychloroquine and azithromycin as a treatment of COVID-19: Results of an open-label non-randomized clinical trial. Int J Antimicrob Agents.

2. Chauhan A, Tikoo A (2015) The enigma of the clandestine association between chloroquine and HIV-1 infection. HIV Med 16: 585-590.

3. Madrid PB, Panchal RG, Warren TK, Shurtleff AC, Endsley AN, et al. (2015) Evaluation of ebola virus inhibitors for drug repurposing. ACS Infect Dis 1: 317-326.

4. Bosseboeuf E, Aubry M, Nhan T, de Pina JJ, Rolain JM, et al. (2018) Azithromycin inhibits the replication of Zika virus. $\mathrm{J}$ Antivirals Antiretrovirals 10: 6-11.
5. Keyaerts E, Li S, Vijgen L, Rysman E, Verbeeck E, et al. (2009) Antiviral activity of chloroquine against human coronavirus OC43 infection in newborn mice. Antimicrob Agents Chemother 53: 3416-3421.

6. Thompson PE, Werbel LM (1972) Antimalarial agents: Chemistry and pharmacology, Medicinal chemistry, Volume 12, New York Academic Press.

7. Coatney GR (1963) Pitfalls in a discovery: The chronicle of chloroquine. Am J Trop Med Hyg 12: 121-128.

8. (2020) Multicenter collaboration group of Department of Science and Technology of Guangdong Province and Health Commission of Guangdong Province for chloroquine in the treatment of novel coronavirus pneumonia. Zhonghua Jie $\mathrm{He} \mathrm{He} \mathrm{Hu} \mathrm{Xi} \mathrm{Za} \mathrm{Zhi} \mathrm{43:} \mathrm{185-188.}$

9. Woosley RL, Heise CW, Gallo T, Tate J, Woosley D, et al. (2020) QT drugs List.

10. Sears SP, Getz TW, Austin CO, Palmer WC, Boyd EA, et al. (2016) Incidence of sustained ventricular tachycardia in patients with prolonged QTc after the administration of azithromycin: A retrospective study. Drugs Real World Outcomes 3: 99-105. 